some way towards answering this question by its careful retrospective analysis of 469 primary tumours of bone. By the very nature of the study and the rarity of the tumour many questions are left unanswered. For the first time however, a iarge number of patients with undoubted osteosarcoma treated in different ways have been subjected to critical analysis. The results, though marred by uncertain factors of selection and not approaching a clinical trial, will be of some help to those responsible for the management of these unfortunate children.

Nowadays most patients in Britain are treated either by primary amputation-about one third-or by a method similar to that advocated by Sir Stanford Cade.' This requires all patients to have radiotherapy as the initial treatment, and reserves amputation only for those whose growth fails to respond or for those more fortunate ones with a reasonable chance of survival in whom no pulmonary metastases are present four to five months after treatment. In this way, about half are spared what, in retrospect, will prove to be an unnecessary amputation.

There are possible disadvantages of this latter method. Firstly, some patients spared amputation because of the early development of metastases might later suffer considerable pain from the effects of late local recurrence. Unfortunately, this doubt cannot be resolved, for there is no reliable information on the incidence of such complications, which if high would be a strong argument in favour of primary amputation. The second theoretical disadvantage of Cade's method is that during the "waiting period" after radiotherapy apparently viable tumour cells-that have been shown to survive in at least one in three primary growths after a full course of radiotherapy-might themselves metastasize. This possibility cannot be denied; but, in spite of it, the working party's findings are that patients treated by primary amputation fared no better in terms of survival than the other group in which all had radiotherapy but where many were spared amputation.

Leaving aside future developments under trial such as chemotherapy, which has shown little promise in osteosarcoma, and the theoretical possibilities of immunotherapy, what then should be the management of a patient with osteosarcoma today? Biopsy is essential and there is no evidence that it is harmful. With the diagnosis established, a full course of radiotherapy should be given. Those patients whose local clinical and radiological response to irradiation is unsatisfactory require amputation. The remainder should be reviewed four to five months later, when about threequarters of those who will die will have already developed their pulmonary metastases, and those whose lungs remain clear will have a good chance of survival. It is this last group of patients who then complete their treatment by amputation at a level above that of the bone involved.

Relief of suffering for those who will die is ensured for most by the initial radiotherapy, but in some also by the ready acceptance of the necessity for late palliative amputation should the need arise. The surgeon should not hesitate to amputate early when signs of recurrence develop if death is not close. At all costs the child must be spared the horror of painful local recurrence, perhaps with pathological fracture or even fungation. Finally there must be close surveillance of those free from pulmonary metastases, in order that the rare opportunity for successful resection of a solitary deposit in the lung is not missed.

Until some better form of treatment emerges, the management of a patient with osteosarcoma must be shared be- tween radiotherapist and surgeon. Their aim is cure. Howcver, for the 80 " who will, in spite of this treatment, dic of their disease, palliation will prove to be a most worthwhile result.

1 Cade S., British Journal of Radiology, 1947, 20, 10.

\section{Disease and Technology}

Just as the health of an individual depends partly on the way he lives and not simply on the aid he gets from such outside agencies as his family doctor or hospital consultant, so with the health of communities and countries. Whatever their stage of development, all countries are exchanging information and staff, offering educational facilities and permanent employment, in the unending battle against disease. That well-developed countries should help the less technically advanced is an obligation generally agreed regardless of mere self-interest, but whethe : these well-off nations should accept so unquestioningly the services of doctors and nurses from the poorer parts of the world may be doubted. For once again the DirectoGeneral of the World Health Organization, Dr. M. G. Candau," has drawn attention to the "grave lack of health manpower, especially in the developing countrics, which tragically retards world progress towards better health." While outside technical aid is still indispensible for many countries-and they themselves gratefully acknowledge itthe building up of their own health services is the outstanding challenge of the 1970s. The sanitary reforms that greatly improved health in Britain during the second half of the nineteenth century have still to get under way in many developing countries-or for that matter to make their full impact on parts of the Mediterranean littoral.

Unfortunately technical advancement is helping to spread diseases as well as to prevent them. Air journeys much shorter than the incubation periods of most diseases are now recognized to be a hazard we must learn to live with, and public health services are having to adapt themselves accordingly. The risks of returning to Britain with latent malaria or typhoid fever are perhaps becoming more generally known. Increasing travel to the tropics will certainly mean greater exposure to diseases less familiar in this country, among them cholera. One case was diagnosed in Britain last year in a man who returned from holiday in Tunisia, and the first recorded spread of the discase to Africa south of the Sahara in the same year was, as Dr. Candau says, the public health event of the year. It underlines the lesson he draws: countries must provide adequate sanitation and develop the basic health and laboratory services that are fundamental to attainment and maintenance of health.

The relentless advance of bilharzia in Africa in the wake of water supplies for irrigation is another worrying result of applied technology. But a third unhealthy byproduct of man's technical activities, air pollution, is essentially a problem for the industrialized countries, though its ill effects certainly spread far beyond their boundaries. A step towards its measurement and eventual control was the establishment last year of an international monitoring network under the W.H.O. It is the first practical attempt to study the matter on a world scale. 1 Official Records of the World Health Organization, No. 188, The
Work of W.H.O. 1970. Gencva, World Health Organization, 1971 .
2 British Medical fournal, 1970, 4, 2, 61. 